\title{
A review of the evolving landscape between the consumer Internet and men's health
}

\author{
Adithya Balasubramanian ${ }^{1}$, Justin Yu ${ }^{1}$, Ashwin Srivatsav ${ }^{1}$, Aaron Spitz ${ }^{2}$, Michael L. Eisenberg ${ }^{3,4}$, \\ Nannan Thirumavalavan ${ }^{5}$, J. Abram McBride ${ }^{6,7}$, Larry I. Lipshultz ${ }^{6,7}$, Alexander W. Pastuszak ${ }^{8}$ \\ ${ }^{1}$ Baylor College of Medicine, Houston, TX, USA; ${ }^{2}$ Department of Urology, University of California-Irvine, Orange County Urology Associates, \\ Laguna Hills, CA, USA; ${ }^{3}$ Department of Urology, ${ }^{4}$ Department of Obstetrics and Gynecology, Stanford University, Stanford, CA, USA; ${ }^{5}$ University \\ Hospitals Urology Institute/Case Western Reserve University, Cleveland, OH, USA; ${ }^{6}$ Scott Department of Urology, ${ }^{7}$ Center for Reproductive \\ Medicine, Baylor College of Medicine, Houston, TX, USA; ${ }^{8}$ Division of Urology, Department of Surgery, University of Utah School of Medicine, \\ Salt Lake City, UT, USA \\ Contributions: (I) Conception and design: A Balasubramanian, J Yu, A Spitz, N Thirumavalavan, LI Lipshultz, AW Pastuszak; (II) Administrative \\ support: None; (III) Provision of study materials or patients: None; (IV) Collection and assembly of data: All authors; (V) Data analysis and \\ interpretation: All authors; (VI) Manuscript writing: All authors; (VII) Final approval of manuscript: All authors. \\ Correspondence to: Adithya Balasubramanian. Baylor College of Medicine, Houston, TX, USA. Email: adithyabala@ricealumni.net.
}

\begin{abstract}
Internet adoption continues to increase as broadband access and mobile connectivity penetrate developing global markets. Alongside increasing adoption, the Internet continues to evolve and usher in new modes of user interaction. Social media and search engines have facilitated the emergence of the participatory web, in which users are able to contribute content, form online communities, and disseminate information. This participatory web is reshaping the patient-physician relationship as patients are able to search for medical information, directly engage with healthcare practitioners through social media, and make therapeutic decisions via online marketplaces. The ability for patients to self-diagnose and self-treat is highly relevant to andrology, given that men have a baseline reluctance to visit healthcare providers. Furthermore, men's health issues such as erectile dysfunction and male infertility are stigmatized, with men turning to the Internet for guidance. The focus of this review is to survey the academic literature that evaluates the quality of online content for four common men's health conditions: hypogonadism, male infertility, erectile dysfunction, and Peyronie's disease.
\end{abstract}

Keywords: Internet; social media; digital health; urology; Web2.0; andrology; men's health

Submitted Jul 03, 2019. Accepted for publication Sep 19, 2019.

doi: $10.21037 /$ tau.2019.09.29

View this article at: http://dx.doi.org/10.21037/tau.2019.09.29

\section{Introduction}

Over 5 billion people, or approximately $57 \%$ of the world's population, have access to the Internet, with adoption poised to continue to increase owing to expanding broadband access and mobile connectivity (1). Alongside a growing user base, the Internet is also evolving. In the early years (circa 1990-2000), the Internet was composed of primitive, static websites that served only to display information (2). Technological limitations including slow Internet speeds and prohibitive costs involved with maintaining websites resulted in large corporations acting as gatekeepers of online information. Given the high barrier to entry, users were relegated to passively consuming information and had limited opportunities to contribute online content.

Advancements in computer science in the late 1990s and early 2000s ushered in new types of use interaction such as blogging, content uploading, and user comments within websites (2-4). These technologies facilitated a transition from passive information consumption to active, user-driven contributions (Figure 1). Users were empowered by this participatory Internet in which networked individuals could 


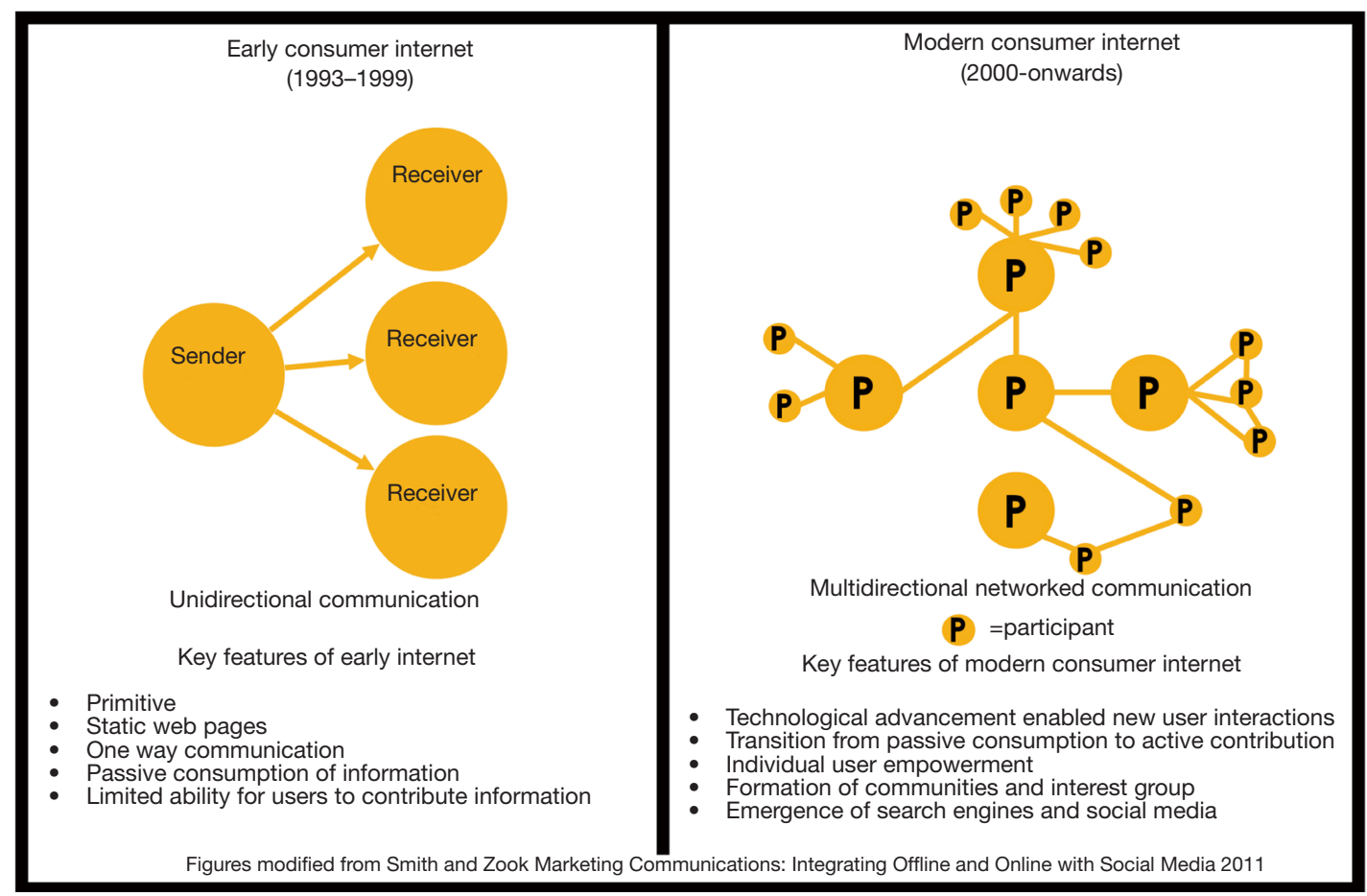

Figure 1 Overview of the early versus modern consumer Internet.

collaborate, develop ideas, and disseminate information within and among online communities (5).

Search engines and social media platforms were conceived amidst these trends and further empowered users. In 2005, the Pew Research Center estimated that 5\% of adults in the United States (U.S.) utilized at least one social media site (6). By 2017, adoption had increased to $69 \%$ (6). Data from the Pew study highlighted that adoption increased across various age groups including the 65 and older demographic, dispelling the belief that Internet participation occurred solely among younger generations.

The participatory web is now reshaping the patientphysician relationship. Patients are now able to search for medical information or directly engage with healthcare practitioners through social media. Patients are also able to document and upload healthcare experiences across their healthcare journeys, including diagnosis, treatment, and recovery. Online communities are enabling patients to interact, offer support, and share personal illness narratives. The democratization of medical information alongside the emergence of online marketplaces has also enabled patients to self-diagnose, self-treat, and consult online peers without engaging with healthcare practitioners. Whether the healthcare community agrees with this approach is irrelevant-patients utilizing freely available information to facilitate their care is likely here to stay.

These trends are particularly noteworthy for andrologists. It is well established that men have an underlying reluctance to visit healthcare practitioners (7). Furthermore, men's health issues such as erectile dysfunction (ED) and male infertility are highly stigmatized, further reducing the likelihood that men will visit a physician $(8,9)$. Sociocultural impediments are reinforced by structural and political barriers such as limited insurance coverage which often excludes coverage for these conditions $(10,11)$. The abundance of online medical information along with the empowerment of the patient to independently make therapeutic decisions raises the importance of understanding the existing landscape between the Internet, social media, and men's health. The focus of this review is to discuss the published literature that evaluates the quality of online content for hypogonadism, male infertility, ED, and Peyronie's disease (PD).

\section{Hypogonadism}

Testosterone is the primary male sex hormone that plays an essential role in male reproduction, development, and 
Table 1 Overview of relevant Internet-based studies for hypogonadism

\begin{tabular}{|c|c|c|c|c|}
\hline Study & Year & $\begin{array}{l}\text { Medium or } \\
\text { study type }\end{array}$ & Main outcomes & Main findings \\
\hline Pirola et al. & 2010 & Case report & Case report & $\begin{array}{l}\text { Patients are purchasing and consuming anabolic steroids } \\
\text { sold on the Internet without consideration for the long- } \\
\text { term impact of these therapies on fertility potential }\end{array}$ \\
\hline Cordaro et al. & 2011 & Websites & $\begin{array}{l}\text { Assessment of popular products } \\
\text { sold on AAS websites }\end{array}$ & $\begin{array}{l}\text { Nandrolone, methandrostenolone and testosterone are } \\
\text { commonly sold on the Internet. Adverse effects of these } \\
\text { drugs were rarely reported on these sites. Suggested } \\
\text { dosages are 2- to 4-fold higher than recommended }\end{array}$ \\
\hline Oberlin et al. & 2015 & Websites & $\begin{array}{l}\text { Assessment of content on } \\
\text { Testosterone-oriented websites }\end{array}$ & $\begin{array}{l}\text { A majority of testosterone-oriented websites were } \\
\text { produced by non-physicians. A majority discussed the } \\
\text { benefits of TTh while fewer than } 30 \% \text { discussed side } \\
\text { effects associated with TTh. Popular benefits of TTh } \\
\text { included improvements in libido, cognitive function, } \\
\text { sports ability and energy }\end{array}$ \\
\hline Ivanov et al. & 2018 & Websites & $\begin{array}{l}\text { Qualitative content analysis of } \\
\text { Testosterone Websites }\end{array}$ & $\begin{array}{l}\text { Testosterone-oriented websites promote the relationship } \\
\text { between androgens, muscle development, sexual } \\
\text { function and overall well-being }\end{array}$ \\
\hline McBride et al. & 2018 & Websites & $\begin{array}{l}\text { Assessment of popular products } \\
\text { sold on AAS websites }\end{array}$ & $\begin{array}{l}\text { Common synthetic AAS featured on these sites included } \\
\text { metandienone, nandrolone decanoate, and stanozolol. } \\
\text { The authors noted that none of these AAS websites } \\
\text { required prescriptions and that the drugs were supplied } \\
\text { by unregulated international pharmaceutical vendors }\end{array}$ \\
\hline
\end{tabular}

AAS, anabolic androgenic steroids; TTh, testosterone therapy.

physique. Serum testosterone levels are regulated by the hypothalamic-pituitary-gonadal (HPG) axis and can be affected by a variety of pathological and natural processes $(12,13)$. Common factors that can lead to low testosterone levels include obesity, diabetes, hormonal dysregulation, and natural aging, among others $(14,15)$.

Hypogonadism is a syndrome characterized by low serum testosterone levels and the presence of symptoms, including low libido, fatigue, and sexual dysfunction. Testosterone therapy (TTh) is a popular treatment for hypogonadism, as evidenced by a substantial increase in TTh prescriptions over the past two decades (16). Despite the popularity of TTh, several studies have shown that TTh is often prescribed without proper clinical indications or used offlabel for unproven medical conditions (17). Additionally, testosterone boosting supplements (T-Boosters), which are often marketed as natural alternatives to TTh, have gained popularity despite limited studies into their efficacy and safety $(18,19)$.

The Internet is emerging as a popular avenue for men to inform themselves about testosterone and TTh (Table 1) (20). A recent survey of popular testosteronerelated websites from the U.S. revealed that content was geared towards motivating the sale of products such as TTh (21). Information on these sites was primarily focused on the relationship between androgens and muscle 
development. Content also highlighted how testosterone products improve sexual function, slow aging, and promote overall well-being.

A number of urologists have scrutinized the veracity of content hosted on websites pertaining to testosterone and TTh. Oberlin et al. sought to characterize the websites that practitioners from five large U.S. metropolitan areas use to promote therapies for androgen replacement (22). A total of 75 popular websites identified via Google search were assessed based on provider type, content and industry affiliations. Most websites in the study did not represent physicians, and only $20 \%$ of these websites disclosed relevant industry relationships. Nearly $95 \%$ of the studied websites touted the benefits of TTh, while fewer than $30 \%$ discussed side effects associated with TTh. In contrast, websites produced by specialists were more than twice as likely to discuss potential side effects of TTh. The popular benefits of TTh proclaimed by most sites included improvements in libido, cognitive function, sports ability, and energy.

A subsequent analysis by McBride et al. assessed the readability, credibility, and quality of online patient-centered information pertaining to hypogonadism and TTh (23). The authors identified popular testosterone-oriented websites using Google search and evaluated content using validated questionnaires, expert opinion, and literature review. The websites included in the study were deemed to be of poor quality and too complicated for the average patient. Once again, most websites were developed by nonphysicians, highlighting the lack of physician-produced information on these topics. Furthermore, fewer than half of the assessed websites discussed appropriate management of hypogonadism or TTh-associated risks. Together, these studies underscore a critical shortage of accessible and accurate online information related to hypogonadism and TTh.

The Internet also enables patients to directly obtain testosterone products, including androgenic anabolic steroids (AAS), without consulting a healthcare practitioner (24). A 2011 study by Cordaro et al. surveyed the products and services offered by 30 AASoriented websites in the U.S. and Europe (25). Popular products hosted on these sites included nandrolone, methandrostenolone, and testosterone. These websites also sold other products such as thyroid hormone, estrogen blockers, and 5 alpha-reductase inhibitors. The authors identified that adverse effects of these drugs were rarely reported on these sites, despite reported dosages being 2 to 4-fold higher than recommended.

A more recent investigation by McBride et al. further characterized the products hosted on AAS websites (26). Common synthetic AAS featured on these sites included methandienone, nandrolone decanoate, and stanozolol. The authors noted that none of these AAS websites required prescriptions and that the drugs were supplied by unregulated international pharmaceutical vendors. These sites also offered medical recommendations regarding AAS cycling protocols and post supplementation cycle recovery information, though these are not supported by evidencebased research.

Popular online marketplaces that are well known to the general public, including Amazon.com, GNC.com and Bodybuilding.com, are vendors of testosterone boosting supplements (T-Boosters) that claim to "naturally" improve hypogonadal symptoms (27). A recent investigation by Balasubramanian et al. highlighted that T-Boosters are prominently showcased on Amazon.com, with numerous product reviews claiming that these supplements can help increase testosterone levels without the need for AAS or TTh, though without validation for these claims. The authors quantitatively and qualitatively evaluated the T-Booster ingredients and the reviews for these products. Their literature review of product ingredients highlighted that limited human studies have evaluated the efficacy of ingredients in T-Boosters with no conclusive findings of efficacy. Furthermore, analysis of top customer reviews for each product demonstrated considerable differences between popular and trustworthy reviews. Popular reviews prominently featured on product pages claimed that these supplements could improve libido, energy, and strength. However, after trustworthy reviews were identified using a proprietary Amazon review analyzing software, a considerable drop in the number of reviews claiming these benefits was observed. Ultimately, the findings of this study highlighted how the Internet enables inflated claims of product efficacy to be publicized to consumers in a manner that can significantly skew a consumer's perspective.

\section{Male infertility}

Infertility is defined as the inability to conceive after 12 months of regular, unprotected intercourse (28). The male factor contributes in up to $50 \%$ of cases and may be the exclusive driver in $20 \%$ of couples (28). Significant psychosocial burden and marital stress are attributed to male infertility. In particular, studies indicate that infertile men 
are at a higher risk of developing major depressive disorder, sleep-related disturbances, and sexual dysfunction (29-31). Contributing factors include limited public awareness and general male avoidance of mental health services (32). As a result of the stigma associated with male infertility, some men have turned to coping mechanisms, such as avoidance, that further compound psychosocial distress (33). Efforts to provide social support and promote public awareness of male infertility remain ongoing areas of investigation.

Online communities are popular avenues for infertile men to overcome the stigma associated with the condition (Table 2) (34). Hanna and Gough investigated user behavior and content hosted on a male-only infertility discussion board (35). Thematic analysis of forum content revealed that the platform was being used by men to cope with the emotional challenges of infertility and to communicate with other infertile men. Commonly discussed topics included the emotional burden of being diagnosed with the condition, available treatment options, and strategies to maintain intimate relationships. The study found that online forums are frequented by infertile men and that online interactivity and anonymity enables these men to be more open and vulnerable about their emotions.

Further work has classified the online social dynamics present within these online portals. Richard et al. characterized these interactions using an analysis of conversations by 199 unique users across two distinct online infertility discussion boards (36). Most forum conversations focused on sharing experiences at the time of diagnosis and appraisal of the best next steps to seek care. Posts also frequently provided emotional support to forum members and messaging reinforced that infertile men were not alone. Conversations were also directed towards helping partners overcome the initial distress that couple's face when first diagnosed with infertility.

Although Internet-based social networking is beneficial for male infertility patients, rigorous evaluation of the informational content about the condition identified deficiencies in online material. Robins et al. critically evaluated the readability and appropriateness of online information for Internet users using validated tools (37). The authors identified popular male infertility websites using Google and found that many were of poor overall quality, readability, and suitability. A key deficiency was that websites for fertility clinics often lacked information about male fertility and primarily framed infertility as a female-driven issue. Website content was highly technical and therefore inappropriate for individuals with limited education. Additionally, few websites included audio-visual materials, which improves information accessibility. Lastly, most websites were infrequently updated and contained outdated information regarding diagnosis and treatment.

Another Google-based survey by Samplaski and Clemsha aimed to appraise online information pertaining to male fertility vitamins based on author type, content, and validity (38). Most websites were produced by industry sources, as well as private clinics and patients. A minority of websites were from academic sources. While studies examining male fertility, vitamins have not found an impact on semen parameters or fertility thus far, most of the studied websites still stated that vitamins improve sperm count, fecundity rates, and overall reproductive outcomes. Few sites included references and several recommended vitamin dosages above recommended dietary allowances (RDA).

The presence of false or inflated claims is not limited to static websites. A recent investigation by Kelly-Hedrick et al. evaluated YouTube videos focused on infertility (39). The authors highlighted the absence of videos describing the negative aspects of undergoing fertility treatment. Although personal videos and patient testimonials constituted a majority of the analyzed content, most videos were focused on sharing pregnancy announcements. These personal videos garnered significantly more likes and comments than informational videos included in the study. The authors highlighted that the prevalence of positive videos and treatment success stories may skew perceptions about the challenges and realities of undergoing fertility treatments. A subsequent analysis by Balasubramanian et al. confirmed these findings by highlighting that popular male infertility-oriented videos with the most likes and views were of low medical quality (40).

Discussions about male infertility are also occurring on Twitter. Balasubramanian et al. analyzed the \#MaleInfertility Twitter community between 2013 and 2018 (41). The number of users and Tweets included within the \#MaleInfertility Twitter discussion increased during the study period, with a majority of the conversations being driven by doctors and advocacy organizations from more than 20 countries. An analysis of popular hashtags included in \#MaleInfertility Tweets indicated that much of the conversation surrounded discussions about assisted reproductive technologies such as in vitro fertilization (IVF) and intrauterine insemination (IUI). Limited discussion about correctable forms of male infertility was associated with the hashtag. A majority of \#MaleInfertility Tweets 
Table 2 Overview of Internet-based studies focused on male infertility

\begin{tabular}{|c|c|c|c|c|}
\hline Study & Year & $\begin{array}{l}\text { Medium or } \\
\text { study type }\end{array}$ & Main outcomes & Main findings \\
\hline $\begin{array}{l}\text { Hanna and } \\
\text { Gough }\end{array}$ & 2018 & Internet forums & $\begin{array}{l}\text { Qualitative analysis of content on male } \\
\text { infertility-oriented forums }\end{array}$ & $\begin{array}{l}\text { Online male only infertility forums are popular } \\
\text { avenues to discuss the condition, cope with } \\
\text { emotional challenges and appraise the best next } \\
\text { steps to seek care }\end{array}$ \\
\hline Robins et al. & 2016 & Websites & $\begin{array}{l}\text { Evaluation of readability, suitability and } \\
\text { quality of male infertility websites }\end{array}$ & $\begin{array}{l}\text { There is a limited amount of high-quality online } \\
\text { information sources related to male infertility. } \\
\text { Many websites exclusively tailor information to } \\
\text { women }\end{array}$ \\
\hline Richard et al. & 2017 & Internet forums & $\begin{array}{l}\text { Qualitative analysis of posts produced by } \\
\text { males on online infertility forums }\end{array}$ & $\begin{array}{l}\text { Online forums can help patients acquire support } \\
\text { from individuals who have encountered a } \\
\text { diagnosis of male infertility }\end{array}$ \\
\hline $\begin{array}{l}\text { Samplaski and } \\
\text { Clemesha }\end{array}$ & 2018 & Websites & $\begin{array}{l}\text { Evaluation of popular websites claiming } \\
\text { pertaining to Vitamins and male infertility }\end{array}$ & $\begin{array}{l}\text { Many websites claim that vitamin } \\
\text { supplementation can improve male reproductive } \\
\text { outcomes despite limited academic literature to } \\
\text { support these claims }\end{array}$ \\
\hline $\begin{array}{l}\text { Balasubramanian } \\
\text { et al. }\end{array}$ & 2019 & YouTube & $\begin{array}{l}\text { Qualitative and quantitative analysis of } \\
\text { male infertility-oriented YouTube videos }\end{array}$ & $\begin{array}{l}\text { Popular male infertility-oriented videos with the } \\
\text { most likes and views are of low medical quality }\end{array}$ \\
\hline
\end{tabular}

included links to a broad array of uniform resource locators (URLs) including academic websites, other social media portals, medical device pages, independent pharmaceutical retailers, fertility clinic sites, and fertility coaches. The heterogeneity of links identified in the study demonstrated that Twitter is being employed to drive traffic to services that can potentially augment the diagnosis and treatment of the condition.

\section{ED}

ED is a common condition in men above the age of 40 , characterized by the inability to attain or sustain an erection for adequate sexual performance $(42,43)$. Men with ED often note feelings of guilt and shame and have difficulty initiating sexual contact and intimacy (44). Despite the availability of treatments such as sildenafil citrate and other phosphodiesterase-5 (PDE5) inhibitors, men with ED increasingly seek alternative avenues to inform themselves about the condition due to a reluctance to discuss symptoms with physicians and high medication costs $(10,45)$.

Various studies have identified the Internet as a popular location to acquire information about ED (Table 3). Baunacke et al. surveyed visitors of a popular German urology-oriented website highlighting common urologic topics that were researched on the Internet (46). ED was in the top two most popular conditions identified by survey respondents. Many survey participants indicated that websites were the first place they sought information on ED. Moreover, many respondents indicated that information on the Internet played an important role in preparing for subsequent ED-related physician encounters. Patients in the study were a mean age of 55 years old, revealing how older men use websites as a source of health information. The authors highlighted several reasons why the Internet has evolved into a prominent information 
Table 3 Overview of relevant Internet-based studies on erectile dysfunction (ED)

\begin{tabular}{|c|c|c|c|c|}
\hline Study & Year & $\begin{array}{l}\text { Medium or } \\
\text { study type }\end{array}$ & Main outcomes & Main findings \\
\hline Andersson et al. & 2011 & $\begin{array}{l}\text { Randomized } \\
\text { controlled trial }\end{array}$ & $\begin{array}{l}\text { Impact of Internet delivered cognitive } \\
\text { behavioral therapy on ED symptoms }\end{array}$ & $\begin{array}{l}\text { A randomized controlled trial of Internet- } \\
\text { delivered cognitive behavioral therapy for ED } \\
\text { can complement in person physician visits }\end{array}$ \\
\hline Davis et al. & 2012 & Google & $\begin{array}{l}\text { Evaluation of relationship between } \\
\text { search engine queries for ED and sexual } \\
\text { health public health campaigns }\end{array}$ & $\begin{array}{l}\text { Search engine activity for ED in the Republic } \\
\text { of Ireland increased following public health } \\
\text { campaigns for the condition }\end{array}$ \\
\hline Liang et al. & 2012 & Review article & $\begin{array}{l}\text { Evaluation of sexual health medications } \\
\text { online }\end{array}$ & $\begin{array}{l}\text { Counterfeit ED medications are accessible } \\
\text { online }\end{array}$ \\
\hline Gaudiano et al. & 2012 & Survey & $\begin{array}{l}\text { A survey of illegal and counterfeit } \\
\text { medicines for ED treatment }\end{array}$ & $\begin{array}{l}\text { Survey of ED medications sold online revealed } \\
\text { that illegal and counterfeit medications are } \\
\text { accessible online }\end{array}$ \\
\hline Zhang et al. & 2014 & $\begin{array}{l}\text { Clinic-based } \\
\text { survey }\end{array}$ & $\begin{array}{l}\text { Assessment of health seeking behavior } \\
\text { for ED online amongst Chinese men }\end{array}$ & $\begin{array}{l}\text { Young men in China employ the Internet as a } \\
\text { first line option to acquire information about ED }\end{array}$ \\
\hline EIAmrawy et al. & 2016 & Review article & - & $\begin{array}{l}\text { Adulterated and counterfeit male enhancement } \\
\text { nutraceuticals supplements for ED are available } \\
\text { online }\end{array}$ \\
\hline Baunacke et al. & 2018 & Websites & $\begin{array}{l}\text { Evaluation of the most common } \\
\text { andrology topics on the Internet }\end{array}$ & $\begin{array}{l}\text { The Internet is emerging as a popular location } \\
\text { for men to acquire information about ED }\end{array}$ \\
\hline $\begin{array}{l}\text { Balasubramanian } \\
\text { et al. }\end{array}$ & 2019 & Amazon.com & $\begin{array}{l}\text { Evaluation of highest rated and } \\
\text { frequently reviewed ED supplements on } \\
\text { Amazon.com }\end{array}$ & $\begin{array}{l}\text { Analysis revealed that limited human studies } \\
\text { have evaluated the efficacy of ingredients in } \\
\text { ED Supplements with no conclusive findings } \\
\text { of efficacy. Authors identified considerable } \\
\text { differences in benefits reported in popular and } \\
\text { trustworthy product reviews }\end{array}$ \\
\hline
\end{tabular}

source for ED. First, ED's insidious nature may enable patients to recognize symptoms and self-diagnose via digital platforms as the condition progressively worsens. Second, the shame associated with ED may drive men to research the condition and pursue at-home treatments prior to seeking help from a medical professional.

Studies examining ED and Internet search habits in Asia have identified similar trends. Zhang et al. characterized health-seeking behaviors among Chinese men desiring medical attention for ED (47). In line with the Baunacke study, Zhang and colleagues emphasized that Chinese patients prefer the Internet as an information source for ED. While older men preferred to initially discuss ED with physicians, many utilized the Internet to subsequently complement in-person visits. Younger men, on the other hand, were inclined to exclusively rely on Internet-based information for both self-diagnosis and self-treatment.
A study by Davis et al. in 2012 aimed to assess whether the advent of ED-oriented public awareness campaigns in the Republic of Ireland led to more Internet searches for the condition (48). Using Google Search Analytics, the authors investigated the temporal relationship between digital public health campaigns focused on ED and resultant Internet search traffic for the condition. The authors determined that concerted, digitally-driven campaigns can motivate the general population to actively seek more information about ED. The study ultimately recommended that online technologies should be integrated into public health campaigns to help lower the stigma associated with ED while heightening the awareness of ED and normalizing its symptoms should be developed in parallel.

Limited studies have evaluated the quality of websites that educate patients about ED. Read and Mati appraised 70 ED websites based on authorship and content (49). 
The authors discovered that a high proportion of these websites were sponsored by the pharmaceutical industry and identified that company-funded websites were biased towards discussing the medical management for the condition with limited or no discussion about psychosocial etiologies of the condition. Although these conclusions are important in the broader discussion of the Internet and men's health, it is critical to consider that other studies have not assessed or confirmed these findings.

Although the amount of critical evaluation of online information pertaining to ED is limited, several studies have investigated online portals designed to sell ED therapies (50). Gaudiano et al. analyzed PDE5 inhibitors acquired from illegal online marketplaces by examining packaging, active substances, and excipients (51). The authors identified that many products from online pharmacies were sold without outer packaging or leaflets containing information about contraindications, side effects, and adverse drug reactions. Even among packaged products, most were counterfeits and lacked accurate documentation about expiration or batch number. When analyzing these supplements based on active ingredients, $30 \%$ of samples either contained lower or higher amounts of active ingredients or two or more ingredients. Similar discrepancies were noted when analyzing excipients. The ramifications of these findings are notable given the fact that Shaeer discovered that over $16 \%$ of PDE 5 inhibitor users obtain these medications via online pharmacies and that $68 \%$ of these users do so without a prescription $(52,53)$.

Nutraceutical supplements that claim to naturally cure ED also have ingredients such as PDE5 inhibitors (54). A recent analysis of popular ED supplements (EDS) on Amazon.com by Balasubramanian et al. found that most included ingredients were exclusively studied in animal or in vitro models (55). Furthermore, the authors identified considerable differences between popular and trustworthy reviews on affiliated online EDS product pages. Popular product reviews claimed that the supplements dramatically improved erection strength and confidence. However, following a culling of untrustworthy product reviews, the author noted a substantial drop in the number of reviews making these claims. The broader conclusions of this study were that patients should be wary of relying upon consumer reviews to inform therapeutic decisions about nutraceutical use.

The Internet is also enabling new digitally driven therapies for ED to emerge. Andersson et al. developed an Internet-delivered cognitive behavioral therapy (ICBT) platform to treat ED (56). The treatment employed in the study required selected patients to undergo seven weekly modules designed to inform patients about the principles of CBT and subsequently provide them with exposure tasks that gradually exposed them to sexual interactions with their partner. As part of this increased exposure, patients were taught strategies and exercises to manage intrusive thoughts and reduce overall anxiety that potentially exacerbated their ED symptoms. The modules included in the study were also designed to include patients' partners. At the end of the study, patients in the treatment group had improved International Index of Erectile Function (IIEF) scores that indicated that they no longer met diagnostic criteria for ED. Although the conclusions from this study need additional validation, the results highlight how interventions delivered via the Internet can produce meaningful improvements for certain men's health conditions.

\section{PD}

PD is a condition in which abnormal collagen deposition leads to fibrosis and scarring of the penile tunica albuginea (57). Patients with PD often present with penile deformity, which progressively leads to curved and painful erections and can interfere with sexual function (58). Men with PD often report feelings of shame and diminished libido due to impaired sexual function (59). Furthermore, men with PD may be hesitant to discuss sexual performance issues with healthcare practitioners, which can lead to depression and low sexual confidence (59). While therapies for PD exist, most are not fully effective, and awareness for these interventions is suboptimal.

Recent work has aimed to elucidate resources that men utilize to acquire information about PD (Table 4). Bole et al. performed a survey-based study on over 700 PD patients and identified that websites were the most popular avenue for men to inform themselves about PD (60). Patients in the study indicated that they primarily visited websites produced by hospitals or government agencies. Other Internet portals such as forums, blogs and chat rooms were less popular. Bella et al. had previously investigated the utility of these sites and highlighted that much of the PD-oriented online content was developed by advocacy agencies (61). Patients who utilized these sites indicated that these portals helped lower stigma and enabled them to further understand PD's etiology and symptoms.

The conversation related to PD has migrated into new social media venues including Twitter. Balasubramanian 
Table 4 Overview of relevant Internet-based studies on Peyronie's disease (PD)

\begin{tabular}{lllll}
\hline Study & Year & Medium & Main outcomes & Main findings \\
\hline Bella et al. & 2007 & Websites/forums & $\begin{array}{l}\text { Overview of common online resources } \\
\text { for PD patients }\end{array}$ & $\begin{array}{l}\text { Websites and forums are employed by patients } \\
\text { to share information about PD }\end{array}$ \\
Bole et al. & 2018 & Questionnaire & $\begin{array}{l}\text { Survey of resources employed by PD } \\
\text { patients to inform themselves about the } \\
\text { condition }\end{array}$ & $\begin{array}{l}\text { The Internet is the most popular location for } \\
\text { patients to acquire information about PD }\end{array}$ \\
$\begin{array}{l}\text { Balasubramanian } \\
\text { et al. } 2019\end{array}$ & Twitter & $\begin{array}{l}\text { Analysis of online Twitter discussions } \\
\text { for male infertility }\end{array}$ & $\begin{array}{l}\text { Discussions about PD are being undertaken on } \\
\text { Twitter }\end{array}$ \\
\hline
\end{tabular}

et al. analyzed Twitter discussions about PD over a 5 -year study period (62). The authors noted a statistically significant increase in Tweet activity and users contributing to the Twitter PD discussion. A majority of notable influencers included doctors and advocacy organizations. Hashtags such as \#Peyronies were employed to structure the conversation. Additional hashtags such as \#Menshealth, \#Curvedpenis and \#Bentpenis were utilized to provide further context to the Twitter discussion. The authors also identified that Twitter was being employed to share links and direct Internet traffic to advocacy, academic, commercial and, alternative social media websites. Although the authors were able to quantitatively and qualitatively characterize the online Twitter discussion for the condition, they acknowledged that future work would be required to understand the downstream effects of these discussions on real world healthcare practitioner and patient behavior.

\section{Conclusions}

The Internet is emerging as a popular location for men to acquire information about common men's health conditions including male infertility, ED, PD, and hypogonadism. Healthcare practitioners must acknowledge that websites, social media portals, and online marketplaces lower the barrier for men to self-diagnose and self-treat these conditions. Although the Internet enables men to overcome their reluctance to visit healthcare providers, substantial improvements in the quality and readability of online content for these and other conditions is needed. As such, physicians should aim to create accurate, validated, and high-quality digital channels for patients to learn about these conditions. Doing so will help reduce affiliated stigma and enable men to seek effective therapies. Encouraging physicians to embrace the conveniences and costeffectiveness of the Internet will also enable patients to access treatments more readily. The Internet will remain a transformative force in healthcare and physicians should take an active role in shaping this technology as a vehicle to empower men to take ownership of their health.

\section{Acknowledgments}

Funding: None.

\section{Footnote}

Provenance and Peer Review: This article was commissioned by the Guest Editors (Larry I. Lipshultz, Alexander W. Pastuszak) for the focused issue "Contemporary Issues and Controversies in Men's Health" published in Translational Andrology and Urology. The article was sent for external peer review organized by the Guest Editors and the editorial office.

Conflicts of Interest: The focused issue "Contemporary Issues and Controversies in Men's Health" was commissioned by the editorial office without any funding or sponsorship. LIL serves as an unpaid editorial board member of Translational Andrology and Urology from Nov 2019 to Oct 2021. LIL and AWP served as the unpaid Guest Editors of the focused issue. Dr. AW Pastuszak: Endo Pharmaceuticals—advisor, consultant, speaker; Boston Scientific-advisor; Antares Pharmaceuticals—advisor; Bayer AG-speaker. Dr. LI Lipshultz: American Medical Systems (speaker); AbbVie (consultant); Lipocine (consultant); Aytu Bioscience (consultant); Endo Pharmaceuticals (speaker/consultant). Dr. A Spitz: Chironhealth.com customer (telemedical platform); 2nd.MD (provide telemedical second opinions); Foresight imaging/TIMS telesurgical (consultant); Revactin.com (prior spokesperson); Endopharmaceuticals (speaker, spokesperson); AbbVie (speaker). Dr. ML 
Eisenberg: Sandstone-advisor; Ro-advisor; Dadiadvisor; Illumesense-advisor; Gilead-consultant. The other authors have no conflicts of interest to declare.

Ethical Statement: The authors are accountable for all aspects of the work in ensuring that questions related to the accuracy or integrity of any part of the work are appropriately investigated and resolved.

Open Access Statement: This is an Open Access article distributed in accordance with the Creative Commons Attribution-NonCommercial-NoDerivs 4.0 International License (CC BY-NC-ND 4.0), which permits the noncommercial replication and distribution of the article with the strict proviso that no changes or edits are made and the original work is properly cited (including links to both the formal publication through the relevant DOI and the license). See: https://creativecommons.org/licenses/by-ncnd/4.0/.

\section{References}

1. Miniwatts Marketing Group. Internet Usage Statistics [Internet]. Available online: https://www. internetworldstats.com/stats.htm

2. Murugesan S. Understanding Web 2.0. IT Prof 2007;9:34-41.

3. Constantinides E, Fountain SJ. Web 2.0: Conceptual foundations and marketing issues. J Direct Data Digit Mark Pract 2008;9:231-44

4. O'Reilly T. What Is Web 2.0: Design Patterns and Business Models for the Next Generation of Software. 2005. Available online: https://www.oreilly.com/pub/a/ web2/archive/what-is-web-20.html

5. Cormode G, Krishnamurthy B. Key differences between Web 1.0 and Web 2.0. First Monday 2008. Available online: https://journals.uic.edu/ojs/index.php/fm/article/ view/2125/1972

6. Pew Research Center. Social Media Fact Sheet. 2018. Available online: https://www.pewinternet.org/

7. Pinkhasov RM, Wong J, Kashanian J, et al. Are men shortchanged on health? Perspective on health care utilization and health risk behavior in men and women in the United States. Int J Clin Pract 2010;64:475-87.

8. Pontin D, Porter T, McDonagh R. Investigating the effect of erectile dysfunction on the lives of men: a qualitative research study. J Clin Nurs 2002;11:264-72.

9. Arya ST, Dibb B. The experience of infertility treatment: the male perspective. Hum Fertil (Camb) 2016;19:242-8.

10. Frederick LR, Cakir OO, Arora H, et al. Undertreatment of erectile dysfunction: Claims analysis of 6.2 million patients. J Sex Med 2014;11:2546-53.

11. Le B, McAchran S, Paolone D, et al. Assessing the Variability in Insurance Coverage Transparency for Male Sexual Health Conditions in the United States. Urology 2017;102:126-9.

12. Ahern T, Wu FCW. New horizons in testosterone and the ageing male. Age Ageing 2015;44:188-95.

13. Giagulli VA, Guastamacchia E, Licchelli B, et al. Serum Testosterone and Cognitive Function in Ageing Male: Updating the Evidence. Recent Pat Endocr Metab Immune Drug Discov 2016;10:22-30.

14. Wu FCW, Tajar A, Pye SR, et al., European Male Aging Study Group. Hypothalamic-pituitary-testicular axis disruptions in older men are differentially linked to age and modifiable risk factors: the European Male Aging Study. J Clin Endocrinol Metab 2008;93:2737-45.

15. Livingston M, Kalansooriya A, Hartland AJ, et al. Serum testosterone levels in male hypogonadism: Why and when to check-A review. Int J Clin Pract 2017. doi: 10.1111/ ijcp.12995.

16. Baillargeon J, Urban RJ, Ottenbacher KJ, et al. Trends in androgen prescribing in the United States, 2001 to 2011. JAMA Intern Med 2013;173:1465-6.

17. Jasuja GK, Bhasin S, Rose AJ. Patterns of testosterone prescription overuse. Curr Opin Endocrinol Diabetes Obes 2017;24:240-5.

18. Rhoden EL, Morgentaler A. Risks of testosteronereplacement therapy and recommendations for monitoring. N Engl J Med 2004;350:482-92.

19. Lattavo A, Kopperud A, Rogers PD. Creatine and other supplements. Pediatr Clin North Am 2007;54:735-60, xi.

20. Mascarenhas A, Khan S, Sayal R, et al. Factors that may be influencing the rise in prescription testosterone replacement therapy in adult men: a qualitative study. Aging Male 2016;19:90-5.

21. Ivanov N, Vuong J, Gray PB. A Content Analysis of Testosterone Websites: Sex, Muscle, and Male AgeRelated Thematic Differences. Am J Mens Health 2018;12:388-97.

22. Oberlin DT, Masson P, Brannigan RE. Testosterone replacement therapy and the internet: an assessment of providers' health-related web site information content. Urology 2015;85:814-8.

23. McBride JA, Carson CC, Coward RM. Readability, credibility and quality of patient information for 
hypogonadism and testosterone replacement therapy on the Internet. Int J Impot Res 2017;29:110-4.

24. Pirola I, Cappelli C, Delbarba A, et al. Anabolic steroids purchased on the Internet as a cause of prolonged hypogonadotropic hypogonadism. Fertil Steril 2010;94:2331.e1-3.

25. Cordaro FG, Lombardo S, Cosentino M. Selling androgenic anabolic steroids by the pound: identification and analysis of popular websites on the Internet. Scand J Med Sci Sports 2011;21:e247-59.

26. McBride JA, Carson CC, Coward RM. The Availability and Acquisition of Illicit Anabolic Androgenic Steroids and Testosterone Preparations on the Internet. Am J Mens Health 2018;12:1352-7.

27. Balasubramanian A, Thirumavalavan N, Srivatsav A, et al. Testosterone Imposters: An Analysis of Popular Online Testosterone Boosting Supplements. J Sex Med 2019;16:203-12.

28. Practice Committee of the American Society for Reproductive Medicine. Diagnostic evaluation of the infertile male: a committee opinion. Fertil Steril 2015;103:e18-25.

29. Babore A, Stuppia L, Trumello C, et al. Male factor infertility and lack of openness about infertility as risk factors for depressive symptoms in males undergoing assisted reproductive technology treatment in Italy. Fertil Steril 2017;107:1041-7.

30. Palnitkar G, Phillips CL, Hoyos CM, et al. Linking sleep disturbance to idiopathic male infertility. Sleep Med Rev 2018;42:149-59.

31. Sahin A, Urkmez A, Verit A, et al. Psychologic and sexual dysfunction in primary and secondary infertile male patients. Arch Ital Urol Androl 2017;89:120-4.

32. Petok WD. Infertility counseling (or the lack thereof) of the forgotten male partner. Fertil Steril 2015;104:260-6.

33. Schmidt L, Holstein BE, Christensen U, et al. Communication and coping as predictors of fertility problem stress: cohort study of 816 participants who did not achieve a delivery after 12 months of fertility treatment. Hum Reprod 2005;20:3248-56.

34. Niederberger C. Re: Searching for Help Online: An Analysis of Peer-to-Peer Posts on a Male-Only Infertility Forum. J Urol 2016;196:1521.

35. Hanna E, Gough B. Searching for help online: An analysis of peer-to-peer posts on a male-only infertility forum. J Health Psychol 2018;23:917-28.

36. Richard J, Badillo-Amberg I, Zelkowitz P. "So Much of This Story Could Be Me": Men's Use of Support in
Online Infertility Discussion Boards. Am J Mens Health 2017;11:663-73.

37. Robins S, Barr HJ, Idelson R, et al. Online Health Information Regarding Male Infertility: An Evaluation of Readability, Suitability, and Quality. Interact J Med Res 2016;5:e25.

38. Samplaski MK, Clemesha CG. Discrepancies between the internet and academic literature regarding vitamin use for male infertility. Transl Androl Urol 2018;7:S193-7.

39. Kelly-Hedrick M, Grunberg PH, Brochu F, et al. "It's Totally Okay to Be Sad, but Never Lose Hope": Content Analysis of Infertility-Related Videos on YouTube in Relation to Viewer Preferences. J Med Internet Res 2018;20:e10199.

40. Balasubramanian A, Yu J, Srivatsav A, et al. MP46-18 A systematic evaluation of You'Tube as an information source for male infertility. J Urol 2019;201:e685.

41. Balasubramanian A, Yu J, Thirumavalavan N, et al. Analyzing Online Twitter Discussion for Male Infertility via the Hashtag \#MaleInfertility. Urol Pract 2019. doi: 10.1097/UPJ.0000000000000066

42. NIH Consensus Conference. Impotence. NIH Consensus Development Panel on Impotence. JAMA 1993;270:83-90.

43. Albersen M, Lue TF. Erectile dysfunction. Prostate Cancer A Compr Perspect 2013;381:973-95.

44. Peate I. Breaking the silence: helping men with erectile dysfunction. Br J Community Nurs 2012;17:310, 312, 314-7.

45. Goldstein I, Lue TF, Padma-Nathan H, et al. Oral sildenafil in the treatment of erectile dysfunction. Sildenafil Study Group. N Engl J Med 1998;338:1397-404. Erratum in: N Engl J Med 1998;339:59.

46. Baunacke M, Groeben C, Borgmann H, et al. Andrology on the Internet: Most wanted, controversial and often primary source of information for patients. Andrologia 2018. doi: 10.1111/and.12877.

47. Zhang K, Yu W, He ZJ, et al. Help-seeking behavior for erectile dysfunction: a clinic-based survey in China. Asian J Androl 2014;16:131-5.

48. Davis NF, Smyth LG, Flood HD. Detecting internet activity for erectile dysfunction using search engine query data in the Republic of Ireland. BJU Int 2012;110:E939-42.

49. Read J, Mati E. Erectile dysfunction and the internet: drug company manipulation of public and professional opinion. J Sex Marital Ther 2013;39:541-59. 
50. Liang BA, Mackey TK. Sexual medicine: Online risks to health--the problem of counterfeit drugs. Nat Rev Urol 2012;9:480-2.

51. Gaudiano MC, Manna L, Rodomonte AL, et al. A survey on illegal and counterfeit medicines for the treatment of erectile dysfunctions in Italy. J Sex Med 2012;9:2130-7.

52. Shaeer O. The Global Online Sexuality Survey (GOSS): the United States of America in 2011 chapter II: phosphodiesterase inhibitors utilization among English speakers. J Sex Med 2013;10:532-40.

53. Chiang J, Yafi FA, Dorsey PJ, et al. The dangers of sexual enhancement supplements and counterfeit drugs to "treat" erectile dysfunction. Transl Androl Urol 2017;6:12-9.

54. ElAmrawy F, ElAgouri G, Elnoweam O, et al. Adulterated and Counterfeit Male Enhancement Nutraceuticals and Dietary Supplements Pose a Real Threat to the Management of Erectile Dysfunction: A Global Perspective. J Diet Suppl 2016;13:660-93.

55. Balasubramanian A, Thirumavalavan N, Srivatsav A, et

Cite this article as: Balasubramanian A, Yu J, Srivatsav A, Spitz A, Eisenberg ML, Thirumavalavan N, McBride JA, Lipshultz LI, Pastuszak AW. A review of the evolving landscape between the consumer Internet and men's health. Transl Androl Urol 2020;9(Suppl 2):S123-S134. doi: 10.21037/tau.2019.09.29 al. An Analysis of Popular Online Erectile Dysfunction Supplements. J Sex Med 2019;16:843-52.

56. Andersson E, Walén C, Hallberg J, et al. A randomized controlled trial of guided Internet-delivered cognitive behavioral therapy for erectile dysfunction. J Sex Med 2011;8:2800-9.

57. Pryor JP, Ralph DJ. Clinical presentations of Peyronie's disease. Int J Impot Res 2002;14:414-7.

58. Nehra A, Alterowitz R, Culkin DJ, et al. Peyronie's disease: AUA guideline. J Urol 2015;194:745-53.

59. Terrier JE, Nelson CJ. Psychological aspects of Peyronie's disease. Transl Androl Urol 2016;5:290-5.

60. Bole R, Ziegelmann M, Avant R, et al. Patient's choice of health information and treatment modality for Peyronie's disease: a long-term assessment. Int J Impot Res 2018;30:243-8.

61. Bella AJ, Perelman MA, Brant WO, et al. Peyronie's disease (CME). J Sex Med 2007;4:1527-38.

62. Balasubramanian A, Yu J, Lipshultz LI, et al. \#Peyronies: An Analysis of Online Twitter Discussion of Peyronie's Disease. Urol Pract 2019. [Epub ahead of print]. 